\title{
Simple technology for recycling phosphate from wastewater to farmland in rural areas
}

\author{
Hisao Ohtake, Kenji Okano, Masashi Kunisada, \\ Hiroyuki Takano, Masaya Toda
}

Published online: 21 November 2017

\begin{abstract}
A simple technology for phosphate $\left(\mathrm{P}_{i}\right)$ recovery has been developed using a bifunctional adsorptionaggregation agent. The bifunctional agent was prepared by soaking calcium silicates in hydrochloric acid solution. Importantly, recyclable calcium silicates were available almost free of charge from the cement industry and also from the steel industry. The acid treatment was essential not only for enhancing the ability of calcium silicates to remove $\mathrm{P}_{i}$ from aqueous solution but also for enabling the high settleability of removed $\mathrm{P}_{i}$. On-site experiments using a mobile plant showed that approximately $80 \% \mathrm{P}_{i}$ could be recovered from anaerobic sludge digestion liquor at a wastewater treatment plant. This technology has the potential to offer a simple, compact service for recycling $\mathrm{P}_{i}$ from wastewater to farmland in rural areas.
\end{abstract}

Keywords Amorphous calcium silicate hydrates .

Bifunctional agent · Mobile plant · Phosphate recovery ·

Wastewater treatment plant

\section{INTRODUCTION}

Various technologies are potentially applicable to phosphate $\left(\mathrm{P}_{i}\right)$ recovery from secondary phosphorus $(\mathrm{P})$ resources such as sewage sludge, incinerated sludge ash, animal manure, and steelmaking slag (Ohtake and Okano 2015). However, their implementation has often been economically infeasible because of the high cost of plant development, construction, and operation. In particular, $\mathrm{P}_{i}$ recovery in small wastewater treatment plants (WWTPs) has been virtually untouched mainly due to cost and labor shortage problems. There are approximately 2100 sewage treatment plants currently operating in Japan. More than $70 \%$ of these plants have the capacity to treat wastewater of less than $5000 \mathrm{t} \mathrm{d}^{-1}$ (approximately 20000 population equivalents (p.e.)) (Okano et al. 2016a). In addition, approximately 1000 small plants are operating to treat blackwater and septic tank sludge in rural areas where no sewage service is available. Since these plants are mostly operated by less than 10 workers, it is hard to embark on $\mathrm{P}_{i}$ recovery which has been considered as an extra service in the wastewater treatment sector. $\mathrm{P}_{i}$ recovery in small WWTPs is likely a common challenge for recycling nutrients from wastewater to farmland in rural areas.

Crystalline calcium silicate hydrates (CSHs) are formed in hyperalkaline, hydrothermal environments (Chen et al. 2009). Crystalline CSHs have a wide range of structures with various $\mathrm{Ca} / \mathrm{Si}$ molar ratios (Shaw et al. 2000). However, only crystalline $\mathrm{CSH}$ with a low $\mathrm{Ca} / \mathrm{Si}$ molar ratio of 1.0-1.2, such as tobermorite $\left(\mathrm{Ca}_{5} \mathrm{Si}_{6} \mathrm{O}_{16}(\mathrm{OH})_{2} \cdot 4 \mathrm{H}_{2} \mathrm{O}\right)$ (Berg et al. 2005) and xonotlite $\left(\mathrm{Ca}_{6} \mathrm{Si}_{6} \mathrm{O}_{17}(\mathrm{OH})_{2}\right)$ (Chen et al. 2009), have been used for $\mathrm{P}_{i}$ removal from wastewater. Namely, they have been used as a seed for hydroxyapatite crystallization to remove $\mathrm{P}_{i}$ from wastewater. However, hydroxyapatite crystallization requires long reaction time in a complicated reactor for $\mathrm{P}_{i}$ removal. Amorphous calcium silicate hydrates (A-CSHs), which had a high $\mathrm{Ca} / \mathrm{Si}$ molar ratio of 2.0 or greater, could be chemically synthesized using unlimitedly available, inexpensive materials such as siliceous shale and $\mathrm{Ca}(\mathrm{OH})_{2}$ (Okano et al. 2013). Importantly, the chemically synthesized A-CSHs could serve not only as a $\mathrm{P}_{i}$ adsorbent but also as an aggregation agent in aqueous solution (Okano et al. 2015). $\mathrm{P}_{i}$ removed by A-CSHs exhibited better settleability, filterability, and dewaterability than $\mathrm{P}_{i}$ precipitated with conventional $\mathrm{CaCl}_{2}$ and $\mathrm{Ca}(\mathrm{OH})_{2}$. Moreover, unlike $\mathrm{CaCl}_{2}$ and $\mathrm{Ca}(\mathrm{OH})_{2}$, no significant carbonate inhibition was observed with $\mathrm{P}_{i}$ removal by A-CSHs. 
Recyclable calcium silicates are available almost free of charge from the cement industry and also from the steel industry. For example, concrete sludge (CS) is an alkaline waste slurry containing CSHs as a major component. CS is abundantly available at construction sites where more concrete materials are generated than required (Okano et al. 2016b). Conventionally, CS has been disposed of as a landfill material after solid-liquid separation followed by neutralization with a strong acid (Tsunashima et al. 2012). However, since this is costly and wasteful, it is desirable to develop an alternative technology option that can valorize unwanted CS for the cement and construction industry. On the other hand, steelmaking slag is the most abundantly available byproduct, which contains calcium silicates as a major component, in the steel industry (Matsubae et al. 2015). Since the amount of steelmaking slag produced by a steelmaking process is very large, it is a matter of great concern for the steel industry to effectively recycle this byproduct.

Previously, we have shown that a substitute for chemically synthesized A-CSHs could be obtained simply by soaking CS in hydrochloric acid solution for a short period of time (Okano et al. 2016b). Like chemically synthesized A-CSHs, the acid-treated CS could serve as a bifunctional adsorption-aggregation agent for $\mathrm{P}_{i}$. Since recyclable calcium silicates such as CS and steelmaking slag are available almost free of charge, this finding may pave the way for the development of a simple, low-cost technology for $\mathrm{P}_{i}$ recovery in small WWTPs. In the present study, we compared the potential of chemically synthesized A-CSHs and acid-treated CS for $\mathrm{P}_{i}$ recovery in small WWTPs using a mobile pilot-scale plant. Based on the results of on-site experiments, we discussed the possibility to offer new technology options, including an on-site $\mathrm{P}_{i}$ recovery service, to small WWTPs for recycling $\mathrm{P}_{i}$ from wastewater to farmland in rural areas.

\section{MATERIALS AND METHODS}

\section{Sample preparation}

A-CSHs, which had a high $\mathrm{Ca} / \mathrm{Si}$ molar ratio of 2.0 or greater, were chemically synthesized using siliceous shale (M-rite) and $\mathrm{Ca}(\mathrm{OH})_{2}$ as described previously (Okano et al. 2013). M-rite was abundantly available from the cement industry. The $\mathrm{SiO}_{2}$ content of M-rite was approximately $76 \%(w / w)$. Autoclaved lightweight concrete (ALC) particles, a byproduct of the building material industry, were employed as control crystalline CSHs (Liu et al. 2001). The ALC particles contained crystalline tobermorite and quartz as principal components. ALC particles were sieved through a $100-\mu \mathrm{m}$-mesh-size stainless steel screen before use.

Unused CS was taken from a ready-mix concrete plant, washed with water, and dewatered using a filter press (AK175, Kyokuto Sangyo Co., Ltd., Tokyo, Japan). The filter cake was subjected to air drying at room temperature and ground using a mortar and pestle to obtain CS particles. Then CS particles were soaked in $1.3 \mathrm{M} \mathrm{HCl}$ at a concentration of $0.1 \mathrm{~g} \mathrm{~mL}^{-1}$ for $60 \mathrm{~min}$ to make acidtreated CS a substitute for chemically synthesized A-CSHs. During the $\mathrm{HCl}$-soaking treatment, the mixture was continuously stirred by a magnetic stirrer at $600 \mathrm{rpm}$ at room temperature. When required, the acid-treated CS slurry was separated into solid and liquid fractions by centrifugation at $2000 \times g$ at room temperature for $10 \mathrm{~min}$. To study the effect of the surface electric charge of particles on $\mathrm{P}_{i}$ settleability, $5 \mathrm{~mL}$ acid-treated $\mathrm{CS}$ slurry was mixed with $100 \mathrm{~mL}$ of $1 \mathrm{M} \mathrm{NaCl}$. The mixture was stirred by a magnetic stirrer at $200 \mathrm{rpm}$ at room temperature for $30 \mathrm{~min}$. Then, solids were recovered from the mixture by centrifugation at $2000 \mathrm{~g}$ at room temperature for $10 \mathrm{~min}$ before being used for $\mathrm{P}_{i}$ settling experiments.

\section{Characterization}

Electron microscopy was performed at $200 \mathrm{kV}$ using an H-800 transmission electron microscopy system (Hitachi Ltd., Tokyo, Japan) and at $1.5 \mathrm{kV}$ using a JSM-7600F scanning electron microscopy (SEM) system (JEOL Ltd., Tokyo, Japan). For SEM analysis, samples were dried overnight under vacuum. Powder X-ray diffraction analysis was carried out using a D8 ADVANCE diffractometer (Bruker AXS K. K., Japan). For X-ray diffraction analysis, samples were dried by heating at $100{ }^{\circ} \mathrm{C}$ for $10 \mathrm{~h}$. The particle size distribution was determined using a Microtrac particle size analyzer (model 9320-X100, Nikkiso Co., Ltd., Tokyo, Japan). The BET specific surface area was measured from $\mathrm{N}_{2}$ adsorption isotherms using an ASAP2400 adsorption analyzer (Micrometrics Inc., Norcross, GA, USA). The chemical composition of CS particles before and after acid treatment was determined using an X-ray fluorescence (XRF) spectrometer (ZSX100e, Rigaku Co., Tokyo, Japan). Heavy metals, including $\mathrm{Cd}, \mathrm{Pb}, \mathrm{Ni}$, and $\mathrm{Cr}$, were determined using a polarized Zeeman atom absorption spectrophotometer (model Z-5300, Hitachi High-Technologies Co., Tokyo, Japan).

\section{$P_{i}$ recovery test}

Preliminary experiments were carried out in laboratory to compare the $\mathrm{P}_{i}$ removability, settleability, and filterability of chemically synthesized A-CSHs, ALC, CS, and acidtreated CS. For laboratory experiments, a synthetic 
anaerobic sludge digestion liquor, designated test solution, was prepared by dissolving $392 \mathrm{mg}$ of $\mathrm{KH}_{2} \mathrm{PO}_{4}, 1.89 \mathrm{~g}$ of $\mathrm{NH}_{4} \mathrm{Cl}$, and $3.36 \mathrm{~g}$ of $\mathrm{NaHCO}_{3}$ in $1 \mathrm{~L}$ of deionized water. The test solution was designed to have essentially the same $\mathrm{P}_{i}$ concentration $\left(272 \mathrm{mg}_{i} \mathrm{~L}^{-1}\right)$ and buffering capacity as a typical anaerobic sludge digestion liquor. $\mathrm{P}_{i}$ recovery experiments were carried out by adding adsorbents to $200 \mathrm{~mL}$ of test solution at varied concentrations. The mixture was stirred at $250 \mathrm{rpm}$ at room temperature. Samples were taken from the mixture at various time intervals and filtered through a $0.22-\mu \mathrm{m}$-pore-size MillexGV filter (Millipore). The filtrate $\mathrm{P}_{i}$ was determined by the molybdenum blue method described by Murphy and Riley (1962). Total $\mathrm{P}$ was determined as $\mathrm{P}_{i}$ after autoclaving a sample at $121^{\circ} \mathrm{C}$ for $30 \mathrm{~min}$ (APHA, AWWA, and WEF 2012). Citrate-soluble $\mathrm{P}\left(\mathrm{C}-\mathrm{P}_{2} \mathrm{O}_{5}\right)$ in recovered products was determined as $\mathrm{P}_{i}$ solubilized by $2 \%$ citric acid (Braithwaite 1987). After $20 \mathrm{~min}$ of $\mathrm{P}_{i}$ removal, the reaction mixture was transferred to a $200-\mathrm{mL}$ graduated cylinder $(4.0 \mathrm{~cm}$ in diameter) to assess the settleability of recovered P. After $10 \mathrm{~min}$ of free sedimentation, $180 \mathrm{~mL}$ (90\% of the original volume) of the supernatant was gently removed using a siphon. Settleability was evaluated by determining the percentage of total $\mathrm{P}$ that remained in the cylinder after siphoning the supernatant.

\section{Mobile plant}

A 1000-L reactor of $1.3 \mathrm{~m}$ height and $1.2 \mathrm{~m}$ diameter was made of 1-cm-thick reinforced plastic and set up on a 1.5tonne motor truck using a steel frame (Fig. 1a). The lower part of the reactor, which had the shape of an inverted circular cone, was designed to collect $\mathrm{P}_{i}$-rich solids by free sedimentation. The reactor was equipped with an agitator having two stirring blades for mechanical mixing. One inlet valve, which was fitted on the top of the reactor, was connected with an accordion hose for inlet water. Another end of the accordion hose was connected to the outlet of a membrane-type solid-liquid separator for digested sludge in a full-scale WWTP (Fig. 1b).

Two outlet valves were fitted on the side of the reactor to drain the supernatant after the free sedimentation of $\mathrm{P}_{i^{-}}$ rich solids. $\mathrm{P}_{i}$-rich solids were withdrawn from the bottom of the reactor through an outlet valve. $\mathrm{P}_{i}$-rich solids were filtered using a self-made filter system on which no mechanical pressure was applied. To prepare the filter system, a 25-cm-diameter filter cloth tube (Public Sheet \#200, Asahi Kasei Geotechnologies Co., Tokyo, Japan) was tied at one end with a flexible plastic band and hooked on a steel pipe frame. Since the filter cloth tube is widely used for civil engineering work, it is tough, easy to handle, and available at a cheap price. A $250-\mathrm{L}$ plastic container was placed under the steel pipe frame to collect the filtrate. This filtration system was set up on the ground beside the motor truck before being used.

On-site $\mathrm{P}_{i}$ recovery experiments were performed using the mobile plant at a full-scale WWTP located in the Osaka area of Japan. This WWTP employs a Bio-P process (alternative anaerobic and aerobic activated sludge process) to remove $\mathrm{P}_{i}$ from wastewater. $\mathrm{P}_{i}$-rich sludge is subjected to anaerobic digestion after being concentrated by centrifugation. After measuring the initial $\mathrm{P}_{i}$ concentration, 8.1-9.8 L of A-CSHs or acid-treated CS slurry (590-720 g dry weight) was added to the reactor in order to set the $\mathrm{Ca} /$ $\mathrm{P}$ molar ratio at 2.0. After 20 min of mixing, $\mathrm{P}_{i}$-rich solids were allowed to settle for $30 \mathrm{~min}$. Then, approximately $830 \mathrm{~L}$ of the supernatant was drained from the reactor by operating the two outlet valves fitted on the side of the reactor (Fig. 1b). The remaining $170 \mathrm{~L}$ of water was withdrawn from the bottom of the reactor and poured into filter cloth bags. After $90 \mathrm{~min}$ of filtration, the filter cake was removed from the bags and taken to a laboratory for chemical analyses. (a)

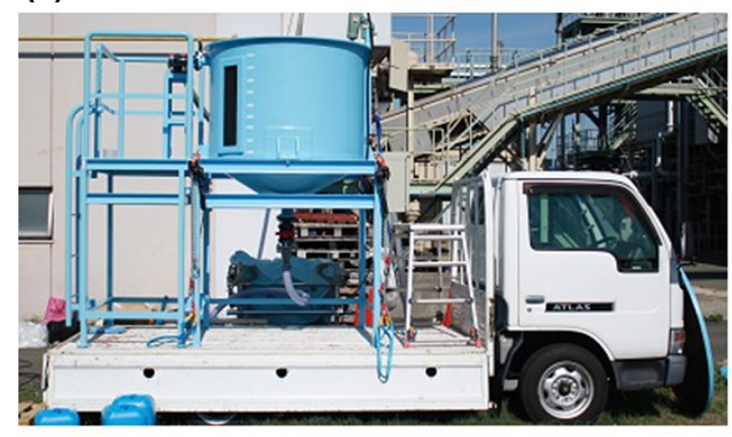

(b)

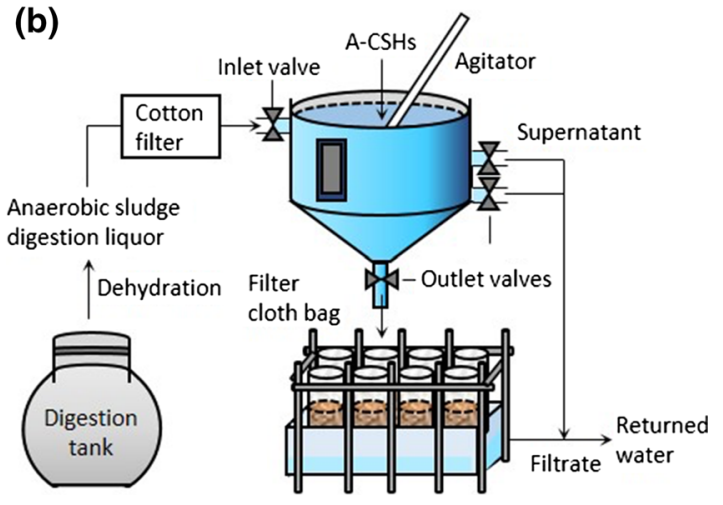

Fig. 1 Mobile plant (a) and the on-site process to recover $\mathrm{P}_{i}$ from anaerobic sludge digestion liquor in a small WWTP (b) 


\section{Plant cultivation test}

Andosol, a dark brown soil originally formed from volcanic materials (Odongo et al. 2007), was used for pot testing. Before potting, the soil was air dried and sieved ( $<2 \mathrm{~mm}$ ). Approximately $410 \mathrm{~g}$ soil was hand-packed into a plastic pot of $6.5 \mathrm{~cm}$ depth and $11.3 \mathrm{~cm}$ diameter. All pots were watered to field capacity. The efficacy of recovered $\mathrm{P}$ product as a $\mathrm{P}_{i}$ fertilizer was compared with those of two commercial $\mathrm{P}_{i}$ fertilizers, Gifu-no-daichi (JA Gifu, Japan) and calcium superphosphate (Kureha Co., Tokyo, Japan). The recovered $\mathrm{P}$ product and Gifu-no-daichi were applied to the plant pots at doses of 100, 200, 300, and $400 \mathrm{mg}$ of C- $\mathrm{P}_{2} \mathrm{O}_{5}$ per pot. Calcium superphosphate was applied to the plant pots at a dose of $100 \mathrm{mg}$ of $\mathrm{C}-\mathrm{P}_{2} \mathrm{O}_{5}$ per pot. Fifty $\mathrm{mg}$ of nitrogen and $42 \mathrm{mg}$ of potassium were applied as ammonium sulfate and potassium chloride to all pots, respectively. Control experiments were conducted by plant pots without the use of fertilizer. To start the plant growth tests, 20 seeds of the leaf vegetable Komatsuna (Brassica rapa L. var. perviridis) were sown on the soil surface. After 3,5 , and 7 days of cultivation, the germination rate was estimated by the naked eye. Leaf length was measured with a ruler after 7, 14, and 22 days of cultivation. Then, all crops were harvested after 22 days of cultivation to measure their live weight.

\section{RESULTS}

\section{Characterization of $\mathbf{P}_{\boldsymbol{i}}$ adsorbents}

The chemically synthesized A-CSHs had a $\mathrm{Ca} / \mathrm{Si}$ molar ratio of approximately 2.0-3.5. This was about 4.1-7.1 times greater than that of $\mathrm{ALC}(\mathrm{Ca} / \mathrm{Si}=0.49)$. The mean particle size of the chemically synthesized A-CSHs was $19 \mu \mathrm{m}$, which was less than that of ALC particles $(21 \mu \mathrm{m})$. Dried A-CSHs had an average surface area of $48 \mathrm{~m}^{2} \mathrm{~g}^{-1}$, approximately 1.3-1.8 times greater than that of ALC particles $\left(38 \mathrm{~m}^{2} \mathrm{~g}^{-1}\right)$. Transmission electron microscopy showed thin platy-layer structures in chemically synthesized A-CSHs and ALC particles. XRD analysis showed that ALC particles exhibited several peaks corresponding to tobermorite and quartz, while dried A-CSHs exhibited several peaks characteristic of $\mathrm{Ca}(\mathrm{OH})_{2}$ (Fig. 2a). A-CSHs showed no peaks corresponding to tobermorite, regardless of whether they were washed with distilled water. Small peaks corresponding to semicrystalline CSHs were observed with A-CSHs at approximately $0.304 \mathrm{~nm}$ (corresponding to $29.4^{\circ} 2 \theta$ ). After removing free $\mathrm{Ca}(\mathrm{OH})_{2}$ by washing, these peaks became more visible at $0.304,0.280$, and $0.182 \mathrm{~nm}$ (corresponding to 29.4, 32.0, and 50.1 $2 \theta$, respectively). This semicrystalline structure was likely formed during drying A-CSHs at $100{ }^{\circ} \mathrm{C}$ for $10 \mathrm{~h}$ (Houston et al. 2009).

The main components of $\mathrm{CS}$ particles were $\mathrm{SiO}_{2}(19.3$ mass \%) and $\mathrm{CaO}$ (41.0 mass\%), indicating that the $\mathrm{Ca} / \mathrm{Si}$ molar ratio was 2.28. The $\mathrm{CS}$ particles also contained significant amounts of $\mathrm{Al}_{2} \mathrm{O}_{3}$ and $\mathrm{Fe}_{2} \mathrm{O}_{3}$ (6.3 and 2.3 mass $\%$, respectively). However, no significant amounts of heavy metals such as $\mathrm{As}, \mathrm{Cd}, \mathrm{Pb}, \mathrm{Ni}$, and $\mathrm{Cr}$ were detected in CS particles. XRD analysis showed that CS particles exhibited several peaks corresponding to quartz, $\mathrm{Ca}(\mathrm{OH})_{2}$, and $\mathrm{CaCO}_{3}$ (Fig. 2b). None of the other peaks were clearly assigned because of the complexity and low crystallinity of hydrated cement (Iizuka et al. 2012). Acid-treated CS showed several peaks corresponding to quartz. However, no significant peak was detected for $\mathrm{Ca}(\mathrm{OH})_{2}$ and $\mathrm{CaCO}_{3}$. Acid-treated CS showed a broad peak in the $2 \theta$ range of $15-40^{\circ}$, suggesting that the amorphous structure of the CS particles became more prevalent after the acid treatment. This was also suggested by the SEM images of CS particles before and after the acid treatment (data not shown).

\section{$P_{i}$ recovery potential}

$\mathrm{P}_{i}$ removal was first examined in laboratory by adding $1.5 \mathrm{~g}$ $\mathrm{L}^{-1}$ of chemically synthesized A-CSHs to test solution at a $\mathrm{Ca} / \mathrm{P}$ molar ratio of 3.5 . Preliminary experiments had shown that this molar ratio was optimal for $\mathrm{P}_{i}$ removal by A-CSHs. The chemically synthesized A-CSHs removed $60 \% \mathrm{P}_{i}$ from the test solution after only 5 min of mixing (Fig. 3a). When the dosage of A-CSHs was increased up to $3.0 \mathrm{~g} \mathrm{~L}^{-1}$, nearly all $\mathrm{P}_{i}$ was removed from the test solution at $5 \mathrm{~min}$ (data not shown). For comparison, ALC particles were added to the test solution at the same concentration of $1.5 \mathrm{~g} \mathrm{~L}^{-1}$. However, ALC particles removed only $8 \% \mathrm{P}_{i}$ from the test solution at $20 \mathrm{~min}$ (Fig. 3a). When the concentration of ALC particles was increased tenfold to $15 \mathrm{~g}$ $\mathrm{L}^{-1}$, about $80 \% \mathrm{P}_{i}$ was removed from the test solution at 20 min (data not shown). In this respect, it must be noted that increasing the dosage of adsorbents unavoidably decreases the $\mathrm{P}_{i}$ content of recovered product on a dry weight basis, thereby lowering its fertilizer value.

The ability of CS to remove $\mathrm{P}_{i}$ from aqueous solution was remarkably enhanced by the acid treatment (Fig. 3b). When $0.5 \mathrm{~g}$ untreated CS particles were added to the test solution at a $\mathrm{Ca} / \mathrm{P}$ molar ratio of 2.5 (the optimum molar ratio for acid-treated $\mathrm{CS}$ ), they removed only $3 \% \mathrm{P}_{i}$ in 60 min. In contrast, acid-treated CS slurry removed $45 \% \mathrm{P}_{i}$ from the test solution in $5 \mathrm{~min}$ at the same $\mathrm{Ca} / \mathrm{P}$ molar ratio. Interestingly, while chemically synthesized A-CSHs and ALC slightly increased $\mathrm{pH}$ in the course of $\mathrm{P}_{i}$ removal, no significant $\mathrm{pH}$ increase was detected with acid-treated CS (Fig. 3c). Since nearly all $\mathrm{Ca}(\mathrm{OH})_{2}$, which existed in 
(a)

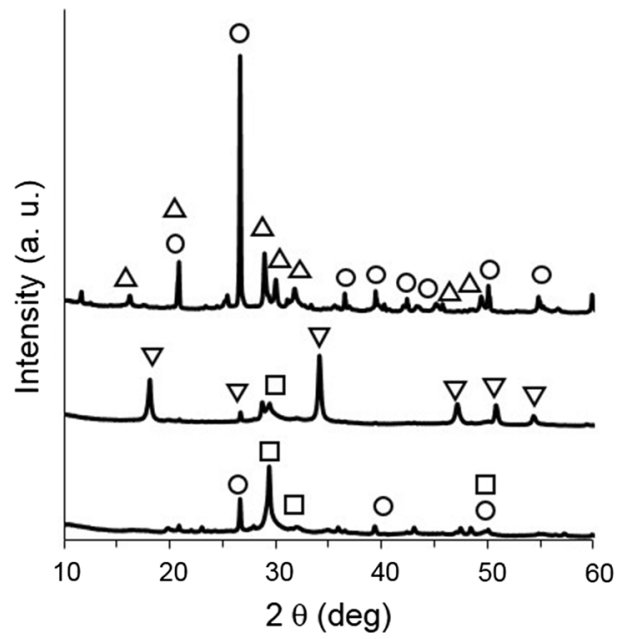

(b)

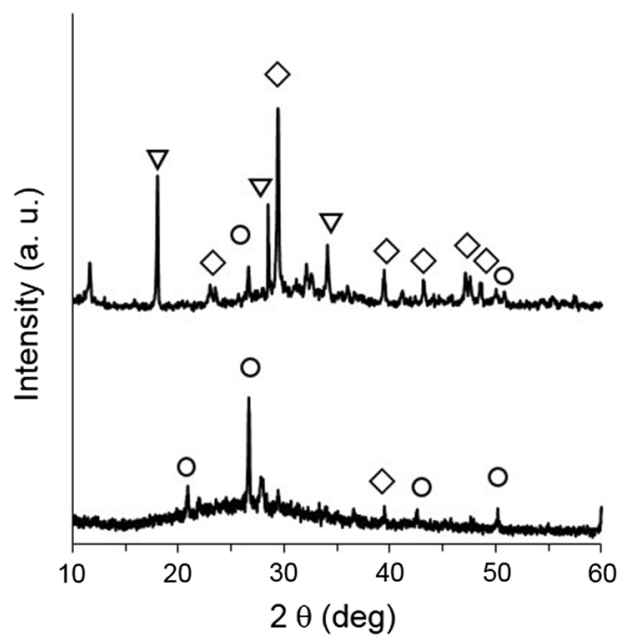

Fig. 2 Powder X-ray diffraction patterns. a ALC particles (top) and chemically synthesized A-CSHs before (middle) and after (bottom) being washed with distilled water. b CS before (top) and after (bottom) acid treatment. Symbols: quartz (circles); tobermorite (triangles); $\mathrm{Ca}(\mathrm{OH})_{2}$ (inverted triangles); semicrystalline $\mathrm{CSHs}$ (squares); $\mathrm{CaCO}_{3}$ (diamonds)

(a)

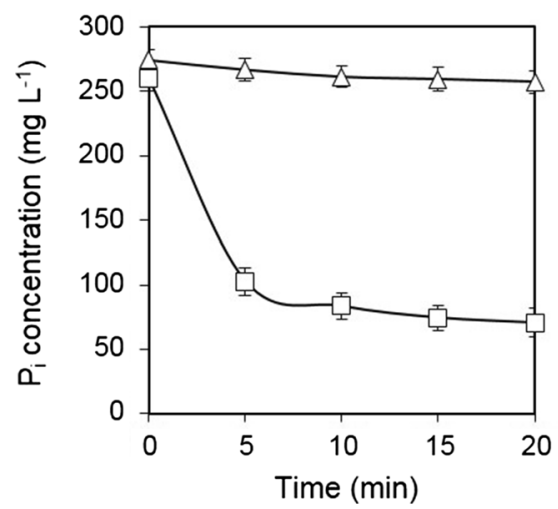

(b)

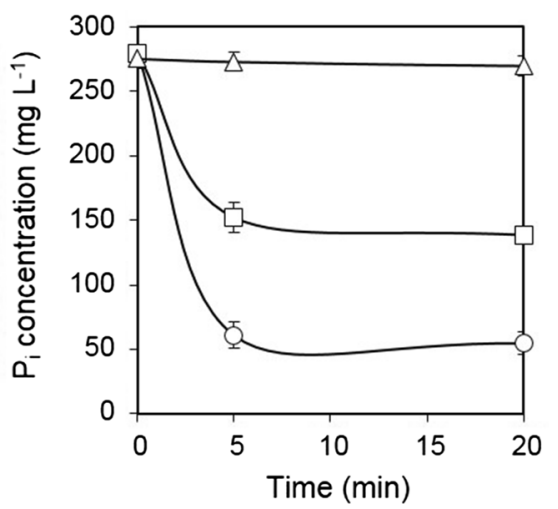

(c)

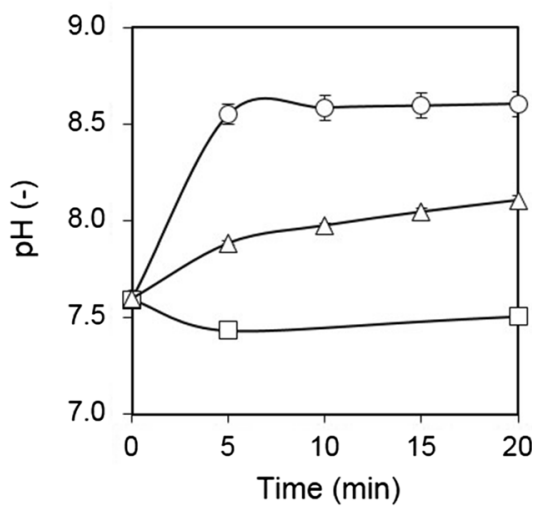

Fig. 3 Time-course data on $\mathrm{P}_{i}$ removal and $\mathrm{pH}$ from test solution. a $\mathrm{P}_{i}$ removal by chemically synthesized A-CSHs (squares) and ALC particles (triangles). b $\mathrm{P}_{i}$ removal by untreated CS (triangles), acid-treated CS (squares), and acid-treated CS at an optimum $\mathrm{pH} 8.5$ (circles). $\mathbf{c} \mathrm{pH}$ changes of the reaction mixture in the course of $\mathrm{P}_{i}$ removal with A-CSHs (circles), ALC particles (triangles), and acid-treated CS (squares). Data points represent the means \pm standard deviations for three independent experiments

$\mathrm{CS}$, was dissolved by the HCl-soaking treatment (see Fig. 2b), no significant release of $\mathrm{Ca}^{2+}$ occurred from the solid fraction of acid-treated CS during $\mathrm{P}_{i}$ recovery (data not shown). This may explain why acid-treated CS did not increase $\mathrm{pH}$ in the course of $\mathrm{P}_{i}$ recovery. It seems to be of practical importance that high $\mathrm{pH}$ is not required for $\mathrm{P}_{i}$ recovery using acid-treated $\mathrm{CS}$. The $\mathrm{P}_{i}$ removal efficiency of acid-treated CS could be changed by changing the initial $\mathrm{pH}$ of the reaction mixture. The $\mathrm{P}_{i}$ removal by acid-treated CS slurry increased when the initial $\mathrm{pH}$ was increased from 7.6 to 8.5 . Acid-treated CS removed $82 \% \mathrm{P}_{i}$ in $5 \mathrm{~min}$ at the optimum $\mathrm{pH}$ of 8.5 (Fig. 3b). When the liquid and solid fractions of acid-treated CS slurry were separated by centrifugation, the solid fraction showed only $6 \% \mathrm{P}_{i}$ removal from the test solution at $60 \mathrm{~min}$. By contrast, the liquid fraction of acid-treated CS slurry removed $63 \% \mathrm{P}_{i}$ from the test solution (data not shown).

Chemically synthesized A-CSHs showed better $\mathrm{P}_{i}$ settleability than did $\mathrm{CaCl}_{2}$ and $\mathrm{Ca}(\mathrm{OH})_{2}$ (Fig. 4). A-CSHs, $\mathrm{CaCl}_{2}$, and $\mathrm{Ca}(\mathrm{OH})_{2}$ settled 78,57 , and $65 \%$ of the total $\mathrm{P}$ from test solution, respectively, after $10 \mathrm{~min}$ of free sedimentation. On the other hand, acid-treated CS could precipitate $72 \% \mathrm{P}_{i}$ in $5 \mathrm{~min}$. Interestingly, the liquid fraction of acid-treated CS slurry showed lower $\mathrm{P}_{i}$ settleability than did uncentrifuged acid-treated CS slurry (data not shown). Uncentrifuged acid-treated CS slurry precipitated approximately $72 \% \mathrm{P}_{i}$ in 5 min of free sedimentation, while only $48 \% \mathrm{P}_{i}$ was settled by the liquid fraction alone. Moreover, $\mathrm{P}_{i}$ precipitation with $\mathrm{CaCl}_{2}$ was significantly enhanced by the addition of the solid fraction of acid-treated CS slurry. 


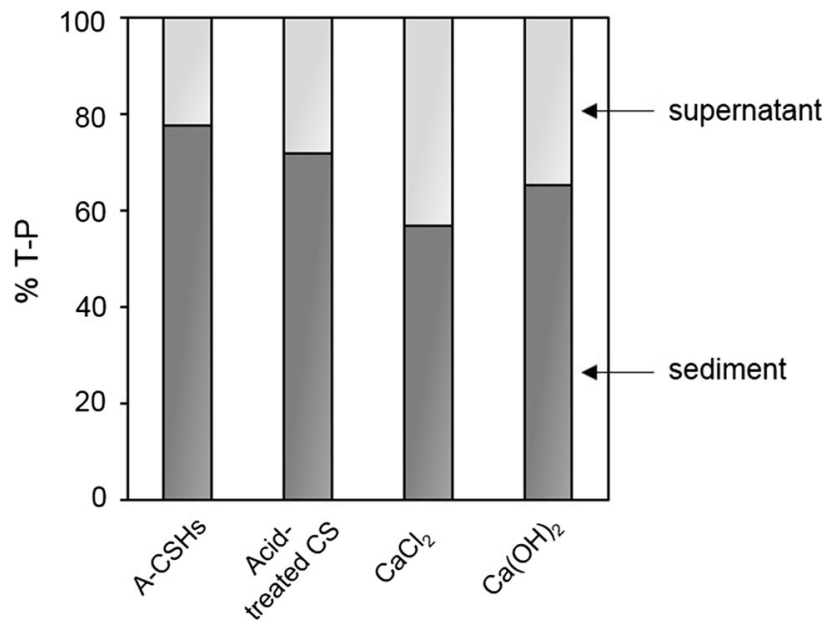

Fig. 4 Settleability test of $\mathrm{P}$ removed by chemically synthesized A-CSHs, acid-treated $\mathrm{CS}, \mathrm{CaCl}_{2}$, or $\mathrm{Ca}(\mathrm{OH})_{2}$. After 20 min of $\mathrm{P}_{i}$ removal, $200 \mathrm{~mL}$ reaction mixture was subjected to $10 \mathrm{~min}$ of free sedimentation. About $180 \mathrm{~mL}$ ( $90 \%$ of the original volume) of the supernatant was gently removed using a siphon. Settleability was evaluated by determining the percentage of total $\mathrm{P}$ that remained in the cylinder (dark gray) after siphoning the supernatant

The enhancement of $\mathrm{P}_{i}$ settleability by the solid fraction was significantly reduced after treatment with $1 \mathrm{M} \mathrm{NaCl}$ (data not shown).

\section{On-site $P_{i}$ recovery test}

On-site $\mathrm{P}_{i}$ recovery tests were carried out at a full-scale WWTP (Fig. 5a) using chemically synthesized A-CSHs and acid-treated CS. The mobile plant was used to recover $\mathrm{P}_{i}$ from anaerobic sludge digestion liquor (rejected water from a membrane-type solid-liquid separator for digested sludge) at the WWTP. In a preliminary run, it was observed that large sludge flocs were present in the anaerobic sludge digestion liquor because of the backwash of the solid-liquid separation membrane for digested sludge. Large sludge flocs unavoidably contaminated recovered $\mathrm{P}$ product and decreased the $\mathrm{C}-\mathrm{P}_{2} \mathrm{O}_{5}$ content on a dry weight basis. To reduce the contamination, anaerobic sludge digestion liquor was passed through a self-made cotton filter before feeding into the reactor (Fig. 1b). The $\mathrm{pH}$ of the anaerobic sludge digestion liquor was nearly constant ranging from 7.7 to 8.1 , while the $\mathrm{P}_{i}$ concentration varied from 168 to $202 \mathrm{mg} \mathrm{P}_{i} \mathrm{~L}^{-1}$.

The $\mathrm{P}_{i}$ recovery experiment was started by adding either chemically synthesized A-CSHs or acid-treated CS slurry to the reactor at a $\mathrm{Ca} / \mathrm{P}$ molar ratio of 2.0 . The $\mathrm{Ca} / \mathrm{P}$ molar ratio was somewhat smaller than that employed in laboratory experiments (i.e., 2.5-3.5). This was required for reducing excess $\mathrm{Ca}^{2+}$ which may leave from the reactor without being used for $\mathrm{P}_{i}$ removal. Soon after the start of the mechanical mixing, both chemically synthesized
A-CSHs and acid-treated CS showed high rates of $\mathrm{P}_{i}$ removal (Fig. 6). They removed approximately $80 \% \mathrm{P}_{i}$ from the anaerobic sludge digestion liquor after $5 \mathrm{~min}$. Then $\mathrm{P}_{i}$ removal gradually increased to $82 \%$ by $60 \mathrm{~min}$. The $\mathrm{pH}$ of the reaction mixture slightly increased to 8.4-8.8 after $60 \mathrm{~min}$ (data not shown).

After $30 \mathrm{~min}$ of free sedimentation, about $830 \mathrm{~L}$ of the supernatant was drained from the reactor (Fig. 5b). Sediments were easily poured into filter cloth bags (Fig. 5c). Then the filtration was carried out without mechanical pressure being applied. As shown in Fig. 5d, the filtrate in the plastic container was clear, suggesting that $\mathrm{P}_{i}$-rich solids were effectively recovered by the filter cloth bags. After $90 \mathrm{~min}$ of filtration, the filter cake was removed from the bags for chemical analyses (Fig. 5e). Mass balance calculation showed that $72-85 \% \mathrm{P}_{i}$ was recovered from the anaerobic sludge digestion liquor, while $13-23 \% \mathrm{P}_{i}$ was lost in the drainage water from the reactor. The loss of $\mathrm{P}_{i}$ due to filtration was only $2-5 \%$. There was no significant difference in the $\mathrm{P}_{i}$ recovery efficiency between chemically synthesized A-CSHs and acid-treated CS. Despite the high $\mathrm{T}-\mathrm{CO}_{2}$ of anaerobic sludge digestion liquor $\left(1280 \mathrm{mg} \mathrm{L}^{-1}\right)$, no carbonate inhibition was observed with $\mathrm{P}_{i}$ removal in the on-site experiments.

\section{$\mathbf{P}_{i}$ recovery products}

No significant difference was observed with the $\mathrm{P}$ products recovered by chemically synthesized A-CSHs and acidtreated CS. The recovered $\mathrm{P}$ product contained $83-87 \%$ moisture before drying for chemical analyses. The ignition loss of the product ranged from 19 to $23 \%$. After drying at $105{ }^{\circ} \mathrm{C}$ for $24 \mathrm{~h}$, the product contained $19-24 \%$ of the dry weight as $\mathrm{P}_{2} \mathrm{O}_{5}$. The $\mathrm{P}_{2} \mathrm{O}_{5}$ content was nearly identical to the $\mathrm{C}-\mathrm{P}_{2} \mathrm{O}_{5}$ content (18-24\%). On average, total potassium $\left(\mathrm{K}_{2} \mathrm{O}\right)$, total nitrogen $(\mathrm{T}-\mathrm{N})$, and $\mathrm{CaO}$ contents were 0.1 , 0.5 , and $38 \%$, respectively, on a dry weight basis. Cd was never detected in the recovered products. The contents of $\mathrm{As}, \mathrm{Pb}, \mathrm{Ni}$, and $\mathrm{Cr}$ were less than 4.0, 4.0, 2.0, and $12.0 \mathrm{mg} \mathrm{kg}^{-1}$, respectively. These values were much lower than their regulatory levels $(840,100,300$, and $500 \mathrm{mg} \mathrm{kg}^{-1}$, respectively) for fertilizer in Japan. When the recovered $\mathrm{P}$ product was applied to andosol at a dose of $100 \mathrm{mg} \mathrm{C}-\mathrm{P}_{2} \mathrm{O}_{5}$ per pot, the germination rate of Komatsuna (Brassica rapa L. var. perviridis) seeds was higher than 90\% after 5 days (data not shown). There was no significant difference in the germination rate between the recovered $\mathrm{P}$ product and the commercial $\mathrm{P}_{i}$ fertilizers (Gifu-no-daichi and superphosphate). Increasing the dose of the recovered $\mathrm{P}$ product had no significant effect on the germination rate. The live weight of Komatsuna was 9.1, 9.5, and $7.8 \mathrm{~g}$ per pot at 22 days after applying $100 \mathrm{mg}$ $\mathrm{P}_{2} \mathrm{O}_{5}$ per pot of the recovered $\mathrm{P}$ product, Gifu-no-daichi, 

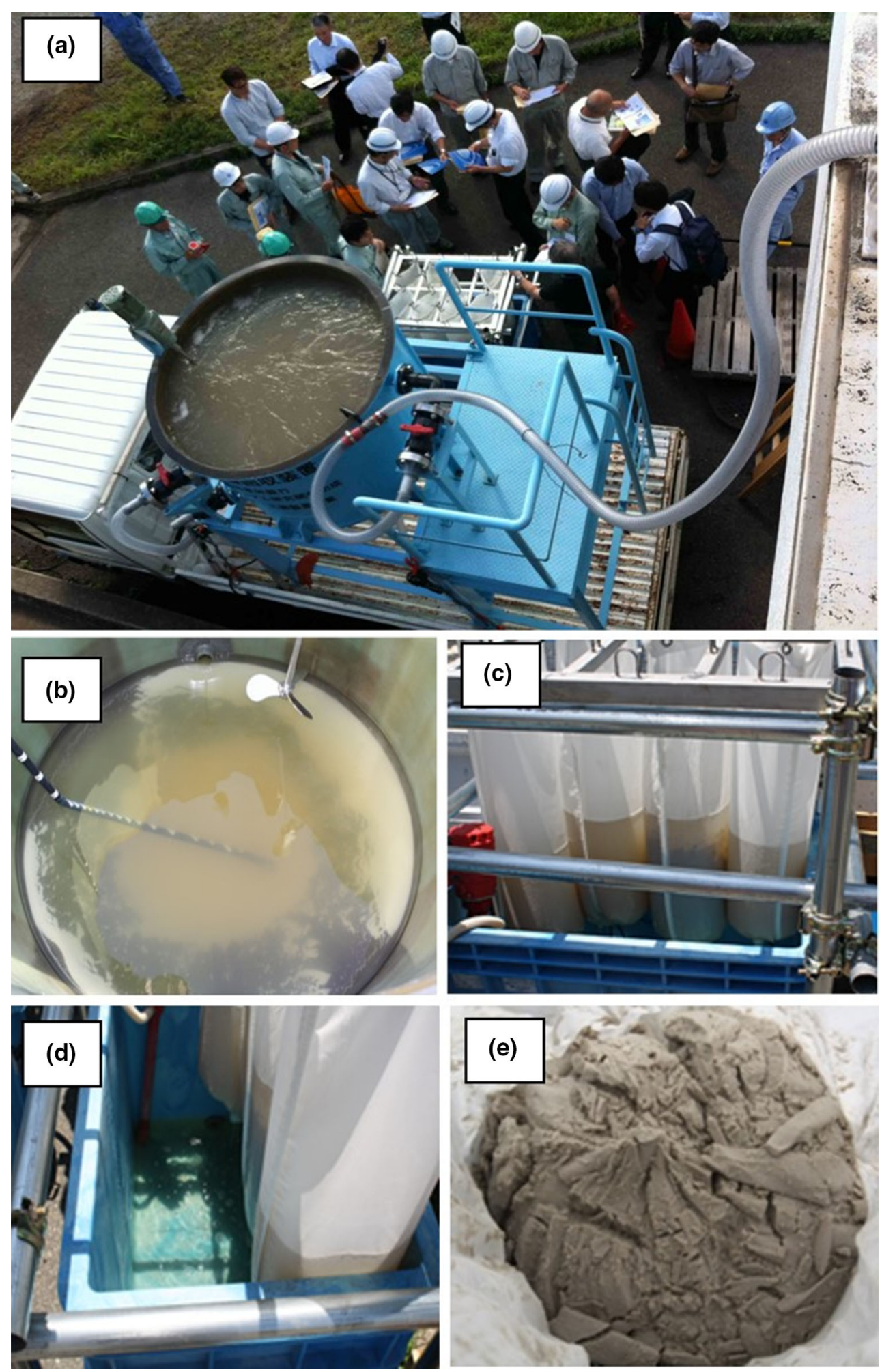

Fig. 5 On-site $\mathrm{P}_{i}$ recovery experiment using a mobile plant. Photographs show the mobile plant $(\mathbf{a})$, the $\mathrm{P}_{i}$-rich solids at the reactor bottom after free sedimentation (b), the filter cloth bags to recover $\mathrm{P}_{i}$-rich solids $(\mathbf{c})$, the filtrate from the filter cloth bags $(\mathbf{d})$, and the recovered $\mathrm{P}$ product $(\mathbf{e})$

and superphosphate, respectively. Komatsuna took up approximately $3.5-4.5 \mathrm{mg} \mathrm{P}$ at 22 days, accounting for approximately $8-10 \%$ of applied P. No significant plant growth was observed without the addition to fertilizer to andosol. The growth of Komatsuna was enhanced by increasing the dose of the recovered $\mathrm{P}$ product. No 


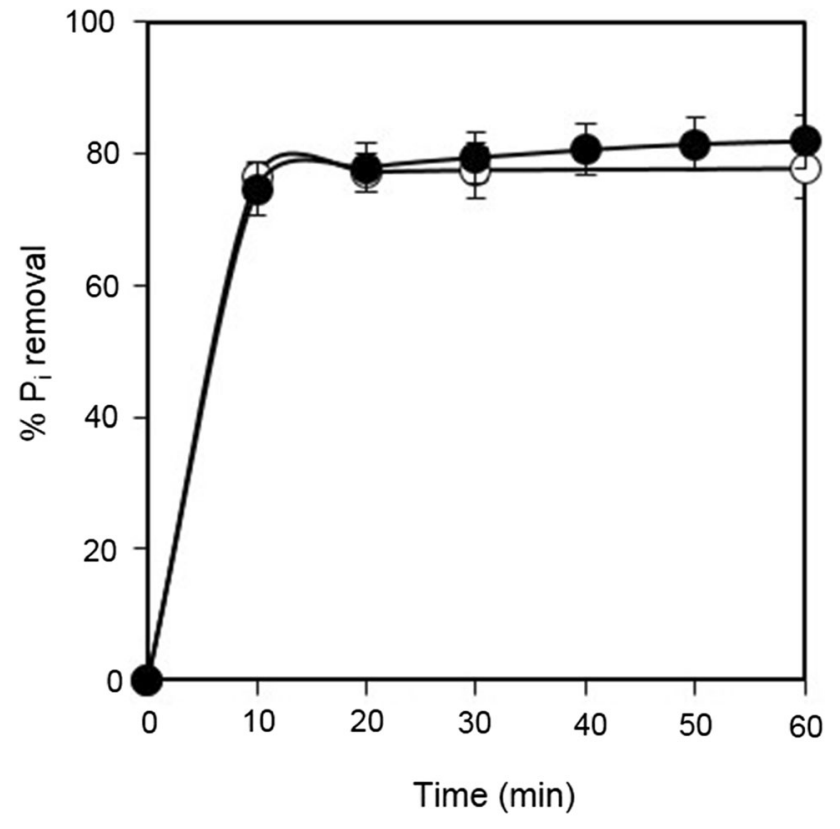

Fig. 6 Time-course data on the $\% \mathrm{P}_{i}$ removal by chemically synthesized A-CSHs (open circles) and acid-treated CS (closed circles) in on-site $\mathrm{P}_{i}$ recovery experiments. Data points represent the means \pm standard deviations for three independent experiments

abnormal plant growth was observed with Komatsuna at the dose of $400 \mathrm{mg} \mathrm{C}-\mathrm{P}_{2} \mathrm{O}_{5}$ per pot.

\section{DISCUSSION}

Chemically synthesized A-CSHs had an average surface area of $48 \mathrm{~m}^{2} \mathrm{~g}^{-1}$, approximately $1.3-1.8$ times greater than that of ALC particles $\left(38 \mathrm{~m}^{2} \mathrm{~g}^{-1}\right)$. While A-CSHs removed $60 \% \mathrm{P}_{i}$ from the test solution after $5 \mathrm{~min}$ of mixing, ACL particles showed only $8 \% \mathrm{P}_{i}$ removal at 20 min (Fig. 3a). Obviously, the high ability of A-CSHs to remove $\mathrm{P}_{i}$ cannot be explained simply by their relatively large surface area. Previously, we have shown that chemically synthesized A-CSHs consisted of silicate polymers that are linked to each other through ion binding with $\mathrm{Ca}^{2+}$ using ${ }^{29}$ Si MAS-NMR analysis (Okano et al. 2015). This structure of A-CSHs was distinctly different from that of tobermorite (Shaw et al. 2000). Tobermorite, which is a principal component of ALC particles (Liu et al. 2001), consists of $\mathrm{CaO}$ polyhedral sheets sandwiched between single silicate chains (Shaw et al. 2000). These composite layers have three types of linkages: $\mathrm{Si}-\mathrm{O}-\mathrm{Si}, \mathrm{Si}-\mathrm{O}-\mathrm{Ca}$, and $\mathrm{Si}-\mathrm{OH}$. The poor P removability of ALC particles is likely due to the poor reactivity of these linkages. Unfortunately, ${ }^{29} \mathrm{Si}$ MAS-NMR analysis failed to show the detailed structure of acid-treated CS because of its high complexity.

Chemically synthesized A-CSHs could readily release $\mathrm{Ca}^{2+}$, when they were dispersed in test solution (data not shown). The initial steps of nucleation of $\mathrm{Ca}-\mathrm{P}_{i}$ in aqueous solution have been speculated using quantum/classical molecular mechanics simulation (Zahn 2004). The molecular mechanics simulation has revealed that a $\mathrm{Ca}^{2+}-$ $\left.\left(\mathrm{HPO}_{4}\right)^{2-}-\mathrm{Ca}^{2+}\right]^{2+}$ aggregate can be formed at the initial stage of nucleation of $\mathrm{Ca}-\mathrm{P}_{i}$ in aqueous solution. Since A-CSHs can acquire negative electrical charges after releasing $\mathrm{Ca}^{2+}$, it seems possible that the $\left[\mathrm{Ca}^{2+}\right.$ $\left.\left(\mathrm{HPO}_{4}\right)^{2-}-\mathrm{Ca}^{2+}\right]^{2+}$ ion triple ionically binds to the negatively charged A-CSHs, forming $\mathrm{Ca}-\mathrm{P}_{i}$-silicate ion aggregates. On the other hand, $\mathrm{P}_{i}$ precipitation with $\mathrm{CaCl}_{2}$ was significantly enhanced by the addition of the solid fraction of acid-treated CS slurry. However, the enhancement of $\mathrm{P}_{i}$ settleability by the solid fraction was significantly reduced after treatment with $1 \mathrm{M} \mathrm{NaCl}$. These results suggested that the surface electric charge of particles in acid-treated CS slurry was also responsible for forming ion aggregates, thereby enhancing $\mathrm{P}_{i}$ settleability.

Recyclable calcium silicates are available almost free of charge from the cement and steel industry. About 197 million tons (Mt) of fresh concrete is produced annually in Japan, and about $1-2 \%$ of fresh concrete prepared for construction is discarded as concrete sludge (Tsunashima et al. 2012). On the other hand, about $15 \mathrm{Mt}$ of steelmaking slag is annually produced in the iron and steelmaking industry in Japan. The valorization of recyclable CSHs is critical to the resource efficiency in the cement and steel industry. Steel slag has been used as a fertilizing material containing $\mathrm{Ca}, \mathrm{Si}, \mathrm{Mg}, \mathrm{Mn}, \mathrm{Fe}$, and $\mathrm{P}$ in China and Japan. Slag-based silicon fertilizers have beneficial effects on the growth and disease resistance of rice (Ning et al. 2014). Actually, Japan has long experience regarding the safe use of slag-based fertilizer in agriculture. The Japanese Fertilizer Regulation Act specifies the upper limit of heavy metals, including $\mathrm{Ni}, \mathrm{Cr}$, and $\mathrm{Ti}$, for slag-based fertilizer. From nutritional perspectives, $\mathrm{Co}, \mathrm{Cr}, \mathrm{Cu}, \mathrm{Mo}, \mathrm{Mn}, \mathrm{Se}$, and $\mathrm{Zn}$ are micronutrients required for plant growth. $\mathrm{V}$ is also considered as a substitute for Mo in plant physiology. There are many types of steel slag produced during the steelmaking process. Since their chemical composition considerably differs, it is possible to select slag that is most suited for target fertilizer.

Although many previous workers have reported the use of crystalline-type CSHs as a $\mathrm{P}_{i}$ adsorbent or a seed for hydroxyapatite crystallization (Berg et al. 2005; Chen et al. 2009), no attempt has been made to enhance the ability of calcium silicates to remove $\mathrm{P}_{i}$ by soaking them in hydrochloric acid. The present technology has the potential to expand the usefulness of recyclable calcium silicates which are abundantly available from the cement and steel industries. The cost related to producing acid-treated CS is comparable to that of disposal by landfill, because the disposal of CS by landfill also needs solid-liquid separation 
followed by neutralization with a strong acid. Rather, if acid-treated CSHs could be used as a substitute for lime, this would significantly improve the resource efficiency of the cement and steel industries.

Like chemically synthesized A-CSHs, acid-treated CS could readily form insoluble ion aggregates with $\mathrm{P}_{i}$, thereby enabling high $\mathrm{P}_{i}$ settleability without adding any other chemical coagulants. $\mathrm{P}_{i}$-rich solids could be recovered by filtration using inexpensive filter cloth bags without mechanical pressure being applied. The recovered $\mathrm{P}$ product had a high $\mathrm{C}-\mathrm{P}_{2} \mathrm{O}_{5}$ content (around $18 \%$ on a dry weight basis). This value was higher than the minimum requirement for $\mathrm{C}-\mathrm{P}_{2} \mathrm{O}_{5}$ ( $15 \%$ on a dry weight basis) in byproduct $\mathrm{P}_{i}$ fertilizer in Japan. The product with a C- $\mathrm{P}_{2} \mathrm{O}_{5}$ content of $15 \%$ or higher could never have been obtained by untreated CS or ALC particles. On the contrary, levels of toxic heavy metals such as $\mathrm{Cd}, \mathrm{As}, \mathrm{Pb}, \mathrm{Ni}$, and $\mathrm{Cr}$ were much lower than their regulation standards for fertilizer in Japan. Since the content of water-soluble $\mathrm{P}_{2} \mathrm{O}_{5}$ in the recovered $\mathrm{P}$ product was less than $0.01 \%$, the recovered product could be used as a slow-release $\mathrm{P}_{i}$ fertilizer.

Land application of sewage sludge is practically prohibited in some countries in Europe as well as Japan. For these countries, it is imperative to recover $\mathrm{P}_{i}$ from sewage sludge in order to locally recycle $\mathrm{P}_{i}$ from wastewater to farmland. In this respect, Japan has long experience in commercial operation of full-scale plants to recover $\mathrm{P}_{i}$ at large-scale WWTPs (Ohtake and Okano 2015). However, since these technologies cost much money for plant construction and operation, they are not suited for $\mathrm{P}_{i}$ recovery in small WWTPs. In Japan, plants having the sewage treatment capacity smaller than $25000 \mathrm{t} \mathrm{d}^{-1}$ (approximately 100000 p.e.) account for about $90 \%$ of operating sewage treatment plants. However, they treat only $25 \%$ of a total of c. $40000000 \mathrm{~m}^{3}$ of sewage per day. Since the $\mathrm{P}$ concentration is comparable, it is likely that smaller sewage works in Japan have the potential to recover approximately $25 \%$ of $\mathrm{P}$ in sewage (c. $13000 \mathrm{t} \mathrm{P} \mathrm{a}^{-1}$ ). In addition to 2100 sewage treatment plants, about 1000 blackwater treatment plants are operating in Japan. Blackwater treatment plants are all small, having the capacity less than $100 \mathrm{~m}^{3}$ of blackwater per day. However, since the T-P concentration of human excreta is typically 200-300 mg P L ${ }^{-1}$ (c. 40-60 times higher than that of sewage), blackwater treatment plants have the $\mathrm{P}$ recovery potential of c. $2300 \mathrm{t} \mathrm{P} \mathrm{a}^{-1}$. Up to now, $\mathrm{P}$ recovery has been implemented in c. 10 blackwater treatment plants, contributing to $\mathrm{P}$ recycling in rural areas.

In the present study, on-site $\mathrm{P}_{i}$ recovery experiments were performed at a sewage treatment plant operating in a Bio-P mode. If $\mathrm{P}_{i}$ is chemically precipitated with $\mathrm{Al}^{3+}$ or $\mathrm{Fe}^{3+}, \mathrm{P}_{i}$ remains in sludge even after anaerobic digestion. This is unfavorable for $\mathrm{P}_{i}$ recovery from sludge slurry.
However, many small plants are operated without nutrient removal in rural areas. Dehydrated sludge is often collected by truck and transported to a remote sludge treatment center. It seems likely that $\mathrm{P}_{i}$ could be recovered from anaerobic sludge digestion liquor or incinerated sludge ash at a remote sludge treatment center. In addition, there is potential for $\mathrm{P}$ recovery in approximately 1000 blackwater treatment plants. The government offers subsidies to $\mathrm{P}$ recovery at blackwater treatment plants to promote $\mathrm{P}$ recycling in rural areas. The mobile plant used in the present study is easily conveyed by a small motor truck and readily installed in a space smaller than $15 \mathrm{~m}^{2}$. Therefore, it seems likely to have the potential to offer a simple, compact service for on-site $\mathrm{P}$ recovery in these small plants. The recovered product could be used as a source of $\mathrm{P}_{i}$ for recycled fertilizer in local areas. For example, the recovered $\mathrm{P}$ product can be added to wood waste compost, thereby increasing its fertilizer value. The $\mathrm{P}_{i}$-amended wood waste compost may be applied to farmland near to a small plant as a recycled organic fertilizer. This could help the local recycling of $\mathrm{P}$ in rural areas.

The amorphous CSHs-based technology for $\mathrm{P}_{i}$ recovery is in an early phase of development. Much work is needed for the automatic control and total cost estimation of $\mathrm{P}_{i}$ recovery process as well as the fertilizer efficacy and safety evaluation of recovered $\mathrm{P}$ products. It may also need to address the quality variation of recyclable calcium silicates, since this can unavoidably affect the performance of bifunctional adsorption-aggregation agents on $\mathrm{P}_{i}$ recovery. However, if these issues are properly addressed, the present technology could offer a simple, compact option to $\mathrm{P}$ recycling from wastewater to farmland in rural areas.

\section{CONCLUSIONS}

A simple technology for $\mathrm{P}_{i}$ recovery has been developed using a bifunctional adsorption-aggregation agent. The bifunctional agent was prepared simply by soaking recyclable calcium silicates in hydrochloric acid solution. Onsite experiments using a mobile plant showed that approximately $80 \% \mathrm{P}_{i}$ could be recovered from anaerobic sludge digestion liquor at a wastewater treatment plant. This technology has the potential to offer new technology options to local small plants for recycling $\mathrm{P}$ from wastewater to farmland in rural areas.

Acknowledgements This work was partly supported by a Grant-inAid for Scientific Research (B) (Grant Number: 25289294) from the Ministry of Education, Culture, Sports, Science and Technology of Japan. We acknowledge Senshu Ikeda Bank, Osaka, and the Mitsui \& Co., Ltd. Environmental Fund, Tokyo, for financial support. We also thank the Toyonaka Chamber of Commerce and Industry for helping us conduct pilot-scale experiments in a WWTP. 
Open Access This article is distributed under the terms of the Creative Commons Attribution 4.0 International License (http:// creativecommons.org/licenses/by/4.0/), which permits unrestricted use, distribution, and reproduction in any medium, provided you give appropriate credit to the original author(s) and the source, provide a link to the Creative Commons license, and indicate if changes were made.

\section{REFERENCES}

APHA, AWWA, and WEF. 2012. Standard Methods for the Examination of Water and Wastewater, 22nd ed., American Water Works Association, American Public Works Association, and Water Environment Federation, Washington, DC.

Berg, U., D. Donnert, A. Ehbrecht, W. Bumiller, I. Kusche, P.G. Weidler, and R. Nüesch. 2005. Active filtration for the elimination and recovery of phosphorus from waste water. Colloids and Surfaces A 265: 141-148.

Braithwaite, A.C. 1987. The use of chemical solubility tests in comparing phosphate fertilizers. Fertilizer Research 12: $185-192$.

Chen, X., H. Kong, D. Wu, X. Wang, and Y. Lin. 2009. Phosphate removal and recovery through crystallization of hydroxyapatite using xonotlite as seed crystal. Journal of Environmental Sciences 21: 575-580.

Houston, J.R., R.S. Maxwell, and S.A. Carrol. 2009. Transformation of meta-stable calcium silicate hydrates to tobermorite: reaction kinetics and molecular structure from XRD and NMR spectroscopy. Geochemical Transactions 10: 1.

Iizuka, A., T. Sasaki, T. Hongo, M. Honma, Y. Hayakawa, A. Yamasaki, and Y. Yanagisawa. 2012. Phosphorus adsorbent derived from concrete sludge (PAdeCS) and its phosphorus recovery performance. Industrial and Engineering Chemistry Research 51: 11266-11273.

Liu, L., J. Ha, and T. Hashida. 2001. Development of a $\mathrm{CO}_{2}$ solidification method for recycling autoclaved lightweight concrete waste. Journal of Materials Science Letters 20: 1791-1794.

Matsubae, K., E. Webeck, K. Nansai, K. Nakajima, M. Tanaka, and T. Nagasaka. 2015. Hidden phosphorus flows related with nonagriculture industrial activities: A focus on steelmaking and metal surface treatment. Resources, Conservation and Recycling 105: 360-367.

Murphy, J., and J.P. Riley. 1962. A modified single solution methods for the determination of phosphate in natural waters. Analytica Chimica Acta 27: 31-36.

Ning, D., A. Song, F. Fan, Z. Li, and Y. Liang. 2014. Effects of slagbased silicon fertilizer on rice growth and brown-spot resistance. PLOS ONE 9: e102681.

Odongo, N.E., K. Hyoung-Ho, H.-C. Choi, P. van Straaten, B.W. McBride, and D.L. Romney. 2007. Improving rock phosphate availability through feeding, mixing and processing with composting manure. Bioresource Technology 98: 2911-2918.

Ohtake, H., and K. Okano. 2015. Development and implementation of technologies for recycling phosphorus in secondary resources in Japan. Global Environmental Research 19: 49-65.

Okano, K., S. Miyamaru, A. Kitao, H. Takano, T. Aketo, M. Toda, K. Honda, and H. Ohtake. 2015. Amorphous calcium silicate hydrates and their possible mechanism for recovering phosphate from wastewater. Separation and Purification Technology 144: 63-69.

Okano, K., S. Miyamaru, Y. Yamamoto, M. Kunisada, H. Takano, M. Toda, K. Honda, and H. Ohtake. 2016a. A mobile pilot-scale plant for in situ demonstration of phosphorus recovery from wastewater using amorphous calcium silicate hydrates. Separation and Purification Technology 170: 116-121.

Okano, K., M. Uemoto, J. Kagami, K. Miura, T. Aketo, M. Toda, K. Honda, and H. Ohtake. 2013. Novel technique for phosphorus recovery from aqueous solutions using amorphous calcium silicate hydrates (A-CSHs). Water Research 47: 2251-2259.

Okano, K., Y. Yamamoto, H. Takano, T. Aketo, K. Honda, and H. Ohtake. 2016b. A simple technology for phosphorus recovery using acid-treated concrete sludge. Separation and Purification Technology 165: 173-178.

Shaw, S., S.M. Clark, and C.M.B. Henderso. 2000. Hydrothermal formation of the calcium silicate hydrates, tobermorite $\left(\mathrm{Ca}_{5} \mathrm{Si}_{6} \mathrm{O}_{16}(\mathrm{OH})_{2} \cdot 4 \mathrm{H}_{2} \mathrm{O}\right)$ and xonotlite $\left(\mathrm{Ca}_{6} \mathrm{Si}_{6} \mathrm{O}_{17}(\mathrm{OH})_{2}\right)$ : an in situ synchrotron study. Chemical Geology 167: 129-140.

Tsunashima, Y., A. Iizuka, J. Akimoto, T. Hongo, and A. Yamasaki. 2012. Preparation of sorbents containing ettringite phase from concrete sludge and their performance in removing borate and fluoride ions from waste water. Chemical Engineering Journal 200-202: 338-343.

Zahn, D. 2004. Mechanisms of calcium phosphate ion association in aqueous solution. Zeitschrift fur Anorganische und Allgemeine Chemie 630: 1507-1511.

\section{AUTHOR BIOGRAPHIES}

Hisao Ohtake $(\bowtie)$ is a Guest Professor of Phosphorus Atlas Research Institute at Waseda University. His research interests include recycling phosphorus from wastewater to farmland. He serves as the chairman of Phosphorus Recycling Promotion Council of Japan.

Address: Phosphorus Atlas Research Institute, Waseda University, Wakamatsu-cho 2-2, Shinjuku-ku, Tokyo 162-0056, Japan.

e-mail: hohtake@bio.eng.osaka-u.ac.jp

Kenji Okano is an Assistant Professor at Osaka University. His research interest is on the efficient use of secondary phosphorus resources with chemical and biological technologies.

Address: Department of Biotechnology, Graduate School of Engineering, Osaka University, 2-1 Yamada-oka, Suita, Osaka 565-0871, Japan.

e-mail: okano@bio.eng.osaka-u.ac.jp

Masashi Kunisada is the President of Mikuni Pharmaceutical Industrial Co., Ltd. His research interests involve the technical use of high-purity phosphorus generated from secondary resources.

Address: Mikuni Pharmaceutical Industrial Co., Ltd., 2-35 Kamisucho, Toyonaka, Osaka 561-0823, Japan.

e-mail: masasi-k@mikuni-seiyaku.co.jp

Hiroyuki Takano is a General Manager of R\&D Department III, Central Research Laboratory of Taiheiyo Cement Corporation. He is in charge of the development of functional materials and technologies to recycle usable materials from various waste products.

Address: Research \& Development Center, Taiheiyo Cement Co., 24-2 Osaku, Sakura, Chiba 285-8655, Japan.

e-mail: hiroyuki_takano@taiheiyo-cement.co.jp

Masaya Toda is a Director and General Manager of Research \& Development Laboratory, Onoda Chemical Industry Co., Ltd. His research interests involve the manufacture of inorganic phosphate fertilizer using secondary phosphorus resources.

Address: Research \& Development Laboratory, Onoda Chemical Industry Co., Ltd., 39-13 Miyamoto-cho, Itabashi-ku, Tokyo 1740054, Japan.

e-mail: toda@onoda-kagaku.co.jp 